
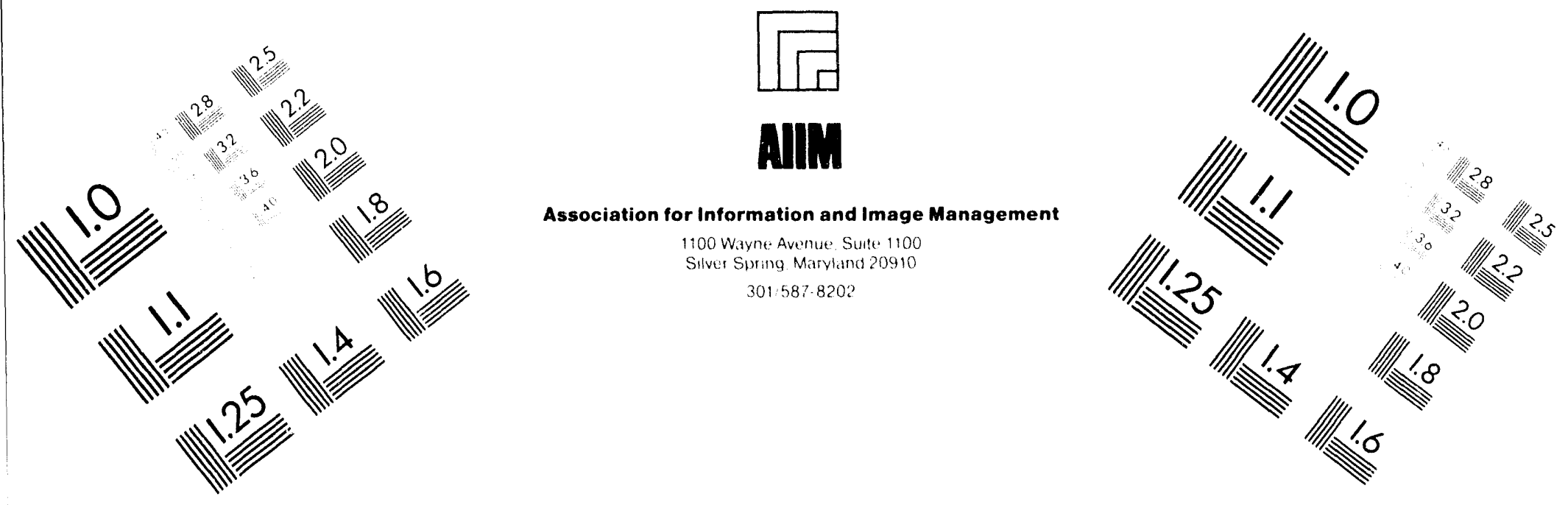

\title{
Centimeter
}

1

Inches
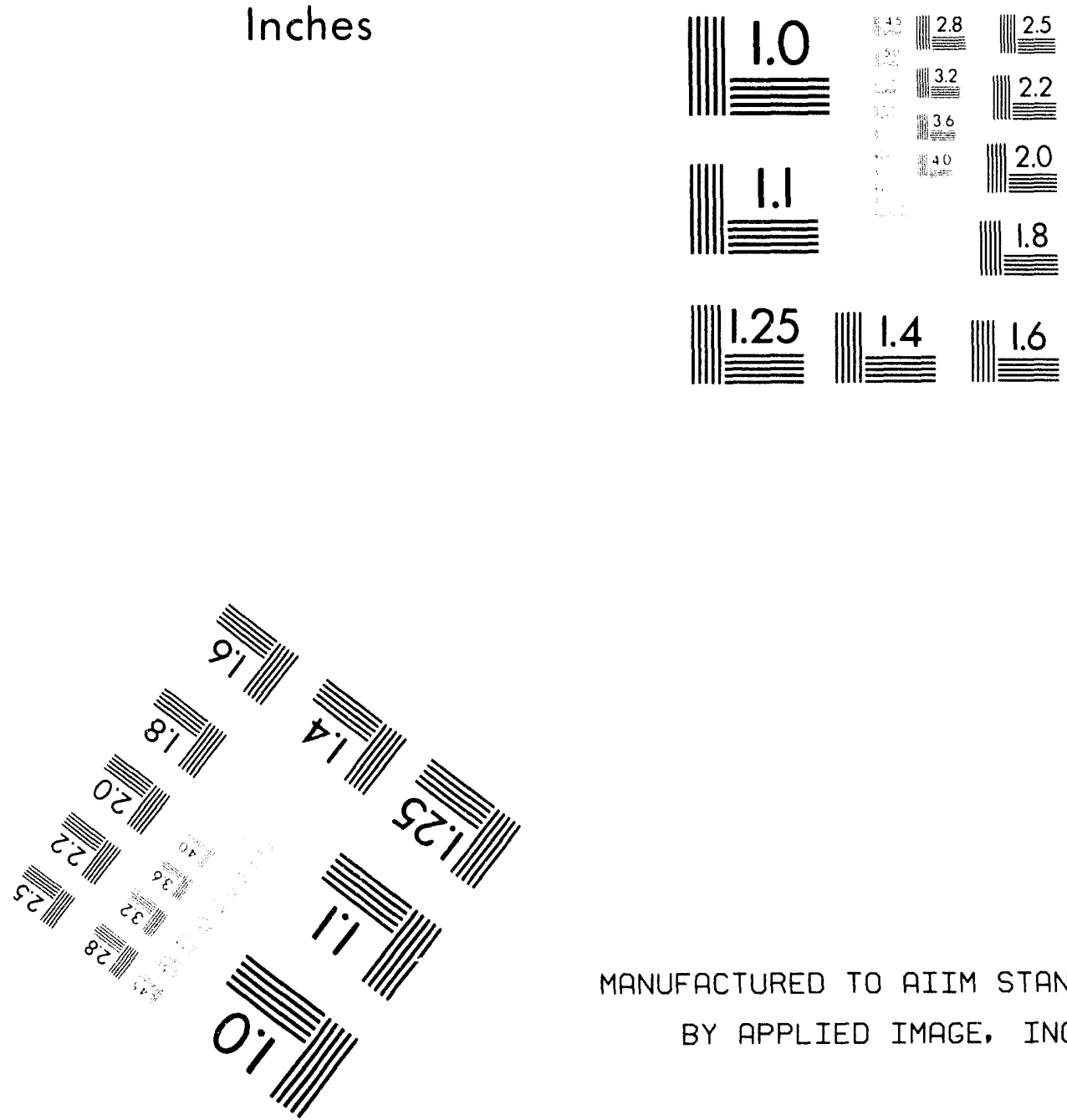

MANUFACTURED TO AIIM STANDARDS

BY APPLIED IMAGE, INC.

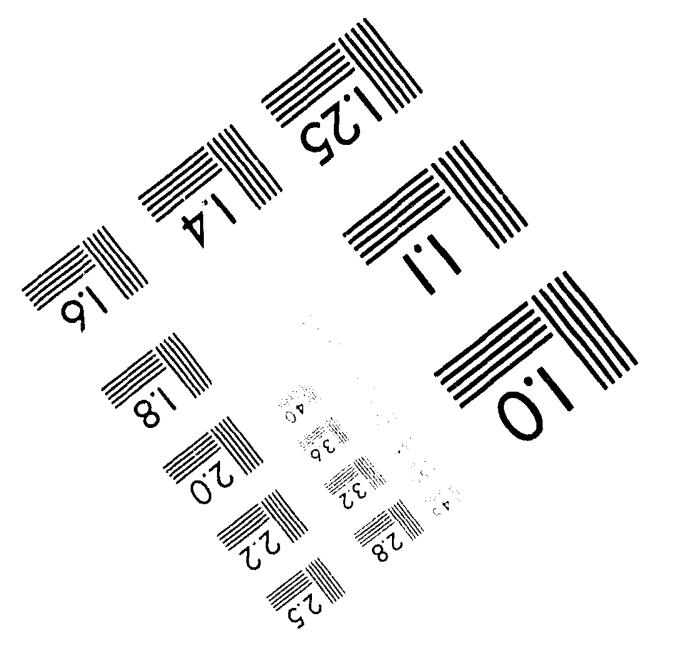



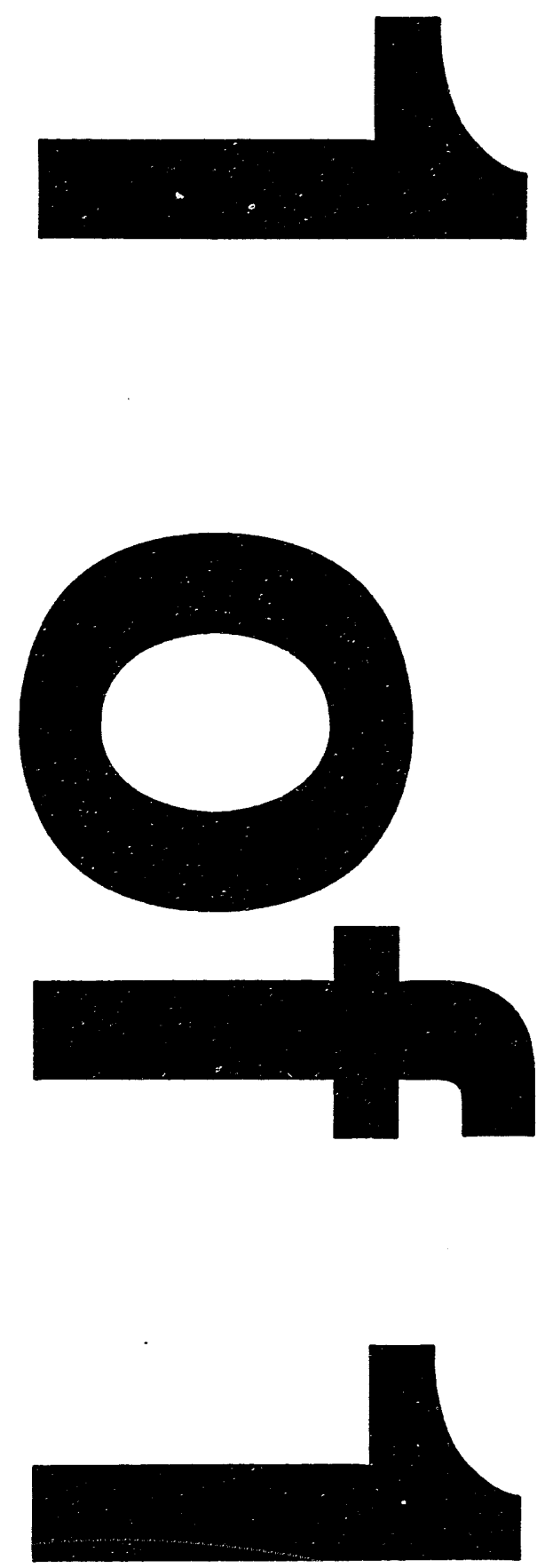


\section{Format and Content Guide for Title 40 CFR 191 and Title 40 CFR 268.6 Compliance Reports}

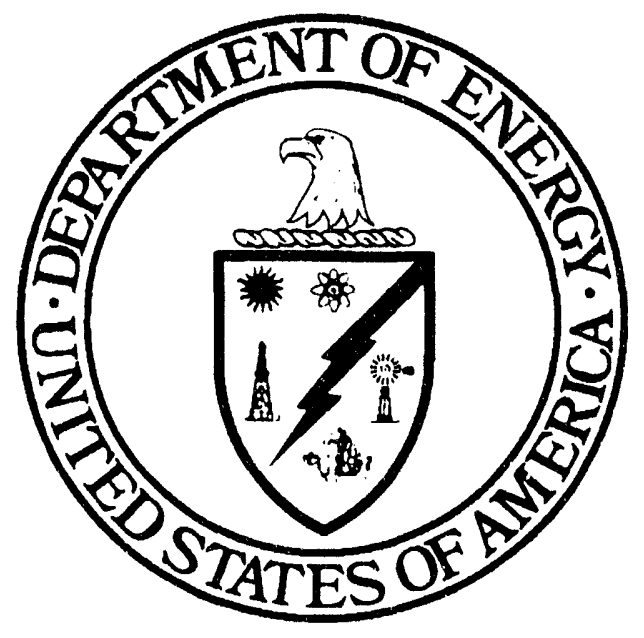

$$
\text { May } 1994
$$

\section{United States Department of Energy} Waste Isolation Pilot Plant

Carlsbad Area Office

Carlsbad, New Mexico 


\section{FORMAT AND CONTENT GUIDE FOR TITLE 40 CFR 191 AND TITLE 40 CFR 268.6 COMPLIANCE REPORTS}

\section{INTRODUCTION}

This Format and Content Guide was followed in preparing the WIPP Compliance Status Report submitted in March 1994 and will be used for the compliance documents scheduled for submittal in the Spring of 1995. The Compliance Status Report was issued to stakeholders in March 1994 and describes the status of associated activities on compliance with the requirements in Title 40 CFR 268.6 and Title 40 CFR 191. The Compliance Status Report focuses on 1) the information required for a demonstration of compliance, 2) preliminary results, 3) the areas of the WIPP program that are either not currently mature enough, or do not provide adequate margin for a demonstration of compliance, and 4) the areas of the WIPP program that will be focused upon to provide the remaining necessary information for use in the 1995 compliance demonstration reports. The Compliance Status Report is not intended to constitute a statement of compliance or a demonstration of compliance. It is intended to report the status of progress made to date in project efforts to achieve the required level of data/information necessary for the required compliance demonstrations. Comments on the Compliance Status Report from stakeholders will likely result in a modified Format and Content Guide, as will the promulgation of the EPA's Compliance Criteria for WIPP (40 CFR 194).

The March 1994 Compliance Status Report was designed to fill several project needs including the following:

1. Focusing the WIPP project on the compliance program and any relevant needs

2. Putting the DOE in a position to receive valuable stakeholder input relative to the appropriateness of the compliance documentation approach and completeness, the appropriateness of the proposed compliance driven experimental programs, and the ability to defend areas where the DOE believes it can demonstrate compliance

3. Establishing a direct link between the proposed experimental programs and needs identified in the compliance evaluation process

The Compliance Status Report differs from subsequent compliance submittals in that the Compliance Status Report does not make a declaration of compliance. Therefore, the 
Compliance Status Report does not provide the exhaustive detail and supporting information that a compliance submittal would need in order for a regulator to make a certification or determination of compliance. The Compliance Status Report focuses on the status of the Project, acknowledging that compliance is not yet documentable. This status involves identifying the areas and system components relevant to compliance, briefly discussing results of the compliance analyses associated with the area/component, and in areas where compliance is not yet achievable, identifying the future action(s) needed to achieve compliance.

\section{TABLE OF CONTENTS}

\section{$1.0 \quad$ INTRODUCTION}

1.1 Project Overview

1.2 Site Selection Process

1.3 Regulatory Framework

\section{DISCUSSION:}

The project overview will include a discussion of the history of the WIPP project. Appropriate information to fulfill this requirement can be referenced in several existing WIPP documents.

The site selection process will be summarized to document that acceptable criteria were used and the appropriate factors were assessed in selection of the WIPP site. The required information can be referenced in the Final Environmental Impact Statement for the WIPP (DOE/EIS-0026), Appendix D.

This section will summarize the requirements of 40 CFR 191, Subparts B \& C and 40 CFR 268.6, and discuss how the document is structured to address these requirements. 


\subsection{SITE DESCRIPTION/SITE CHARACTERIZATION}

2.1 Geology

2.1.1 History

2.1.2 Stratigraphy

2.1.3 Geomorphology

2.1.4 Structural and Tectonic Setting

2.1.5 Surface and Subsurface Features

2.1.6 Geochemistry

2.1.7 Geomechanical Characteristics

2.2 Surface and Groundwater Hydrology

2.2.1 Geochemistry

2.2.2 Hydrological Characteristics

2.2.3 Applicable Natural Processes

2.3 Resources

2.3.1 Resource History

2.3.2 Natural, Extractable, Economic, Cultural

2.4 Background Environmental Conditions

2.5 Climatology and Meteorology

2.5.1 Historical Conditions

2.5.2 Current Conditions

2.5.3 Future Projections

2.6 Summary of Natural Processes

2.6.1 Conceptual Assessment of Future Site Conditions

2.6.2 Summary of Natural Events and Processes

2.6.3 Summary of Projected Performance of Natural Barriers

\section{DISCUSSION:}

This section will include a thorough discussion of the facility's natural environment, since the natural setting is critical to an assessment of adequate repository performance. 
Geological descriptions must include both regional and local geology including structure. subsurface geology. geomorphology, geologic stability, soils, and topography. Site-specific information will be provided to the extent possible. Discussions of groundwater hydrology must include a comprehensive description of regional, local, and site-specific groundwater features. The information shall include identification of aquifers, confining layers, and perched water tables; hydraulic conductivity and storage; groundwater elevations and seasonal variations; aquifer interconnections; flow rates, directions of flow, and areas of recharge/discharge: and locations of wells that withdraw groundwater in the vicinity of the facility.

Surface water hydrology descriptions, like groundwater, will include regional, local, and site features that influence su-face water movements. Maps depicting flood plains and relevant facility features serving to control run on and run off will be of particular interest to the regulator(s) performing the evaluation. Background air, soil, and water quality must be determined and discussed to allow for an assessment of the short-term and long-term impacts of the facility on the environment. The necessary information can be referenced in Chapter 4 of the NMVP; with supporting information located in Appendices $J$ and $L$ and in Addendum 4.0. More current information can be referenced in Chapters B and E of the WIPP RCRA Permit Application.

Applicable, naturally occurring processes that could affect projected repository performance must be described. These discussions must include a summary of applicable historical events and processes, projections of future site conditions, and a summary of the expected performance of the facility relative to natural barriers. 


\subsection{FACILITY DESCRIPTION}

3.1 Design Specifications

\subsubsection{DOE Facility Acquisition Process}

3.2 As-built Design

3.3 Facility Boundaries

3.4 Engineered Barriers

3.4.1 Seals and Plugs

3.4.2 Backfill

3.5 Performance of Engineered Systems

3.5.1 Disposal Phase

3.5.2 Decommissioning Phase

3.5.3 Closure/Post-Closure Phase

3.6 Operations

\subsubsection{Disposal Operations}

3.6.2 Decommissioning

3.6.3 Closure/Post-Closure Operations

3.6.4 Contingency Planning and Emergency Response

3.6.5 Waste Removal

3.6.6 Waste Management and Safety Training

3.6.7 Reclamation and Restoration Activities

3.6.8 Active and Passive Controls

\section{DISCUSSION:}

The DOE will provide adequate detail to acquaint the reviewer with the overall facility and its operations. The information included will consist of a detailed facility design, the facility layout, a discussion of operating plans, the nature of the services to be provided by the facility, the location of the facility, and appropriate points of contact. In addition, a discussion of the level of independent review that the DOE obtains through its facility acquisition process will be included. The information provided will include a description of procedures designed to prevent haza $\cdots$, contingency plans for addressing hazardous situations that may occur, personnel training plans, facility closure and post-closure plans, decommissioning plans, waste removal operations, and reclamation and restoration activities. The DOE will also include a description of the anticipated performance of the repository and applicable waste isolating features of the repository to include both natural and engineered barrier system components. For compliance submittals, each individual components' characteristics may be described in detail, with its performance 
requirements and its addition to the total confinement capability of the repository.

The WIPP design development process will be described. The development of the WIPP repository long-term design is managed by making iterative assessments of planned active and passive institutional controls, repository design and engineered barriers, and potential engineered alternatives. The iterative process of long-term design development provides input to. and receives input from, the performance assessment, which supports the consideration of and potential development of specific modified design elements. This approach will allow for the modification of specific design elements in response to results of performance assessments to mitigate uncertainties where necessary and/or appropriate. The eventual final facility designn will become a portion of the facility technical baseline to be used in compliance demonstrations.

The relevant information and appropriate level of detail that will be included is similar to that in Chapters B, D, F, G, H, I, and J of the WIPP RCRA Permit Application, and in Chapters 1, 2 , and 3 of the NMVP. Appendices $C$ and $J$, and Addendum 1.4 contain some additional supplementary information that will likely be useful. The information in the RCRA Permit Application will require some modification as it currently addresses the WIPP Test Phase only. 


\subsection{WASTE DESCRIPTION}

4.1 Waste Inventory
4.1.1 CH Wastes
4.1.2 RH Wastes

4.2 Waste Envelope

4.2.1 Bounding Criteria Based on Projected Disposal System Performance

4.2.2 Inventory Control

\subsection{Waste Characterization}

4.3.1 Plans and Programs Summary

4.3.2 Waste Forms

4.3.3 Analytical Methodolugies

4.3.4 Waste Characterization Information Summary

4.3.3.1 Process Knowledge Information

4.3.3.2 Analytical Data

\subsubsection{Future Waste Characterization Activities}

\subsection{Waste Related Processes in the Repository Environment}

\subsubsection{Interactions With Natural Barrier Systems}

\subsubsection{Physical Processes \\ 4.4.1.2 Chemical Processes}

\subsubsection{Interactions With Engineered Barrier Systems}

\subsubsection{Physical Processes \\ 4.4.2.2 Chemical Processes}

\section{DISCUSSION:}

This section will include identification and discussion of the specific family of wastes to be managed at the facility. A demonstration that the wastes are compatible with one another and with the facility will also be provided. The DOE will include specific information relative to the waste types and the sources of the wastes, applicable RCRA waste codes, descriptions of the waste generating processes, anticipated waste quantities, and any other relevant chemical and/or physical properties of the wastes that may affect the performance of the repository. A summary of the analytical methodologies to be used in waste characterization activities will also be 
provided. This will be supported by discussions documenting the DOE's knowledge of the waste generating processes and/or hard analytical data where required. A discussion of future plans for waste characterization activities will also be discussed. For example, implementation of Site Treatment Plans as required by the Federal Facilities Compliance Act may result in waste forms which have not been considered in PA analyses, and would be considered in such a discussion of future waste characterization activities.

It will be necessary to discuss the Performance-Based Waste Envelope, the Performance-Based Waste Acceptance Criteria, and their relation to the phased approach and projected repository performance. It will also be necessary to discuss any strategies relative to waste inventory control and load management that may be employed to enhance repository performance while maintaining as flexible a set of Waste Acceptance Criteria as possible. Waste characterization program descriptions will be sufficiently detailed to allow for 1) an assessment demonstrating that the proposed acceptable wastes are compatible, 2) modeling of waste/waste and waste/repository interactions, and 3) modeling potential waste constituent migration pathways and rates of migration toward the boundary of the unit. The assessments will address projected chemical and physical processes involved in interactions between the wastes and both the natural and engineered barrier system components. The DOE will discuss the potential(s) for leachate formation and potential volatilization of organics such that transport/migration toward the unit boundary is feasible. The waste compatibility assessments will also address the potential solubilization and mobilization of hazardous constituents, and must include all components of the waste disposal system. Mechanisms, particularly where waste-related transformations could result in alterations to the original waste toxicity and/or mobility must also be addressed. These mechanisms shall include, at a minimum, biodegradation, hydrolysis, oxidation/reduction, and volatilization. Transformations related to, or driven by the presence of radiation must also be considered.

Relevant information can be referenced in Chapter 3 of the NMVP, Appendices B and N of the NMVP, and Chapter $C$ of the WIPP RCRA Permit Application. The EPA has indicated that additional information, above what was provided in the Test Phase NMVP, will be required in the Disposal Phase NMVP. The required additional information is detailed in Section 7 of the Conditional No-Migration Determination (NMD) for the WIPP. 


\subsection{MONITORING}

5.1 Operational Monitoring

5.2 Confirmatory Monitoring

5.3 Post-closure Monitoring

\section{DISCUSSION:}

Sufficient discussion will be included to justify the proposed design of the monitoring systems and the monitoring program. The operational systems and program shall be adequately described and defended to convince the reviewer that any migration of hazardous constituents and/or radionuclides from the unit will be detected at the earliest time possible. For the operational time-frame, monitoring activities will appropriately be focused on the air pathway. The EPA has stated in the Test-Phase No-Migration Determination that the only credible release pathway from the unit is by way of airborne emission. The WIPP has already installed the appropriate equipment, demonstrated operationally that the appropriate monitoring programs can be implemented, and demonstrated that the equipment can be operated as required to ensure any potential airborne emissions of both radioactive and/or hazardous constituents will be detected as early as is feasible. Long-term activities shall be described that assess facility performance rather than detecting potential contaminant migration via the soil and/or water pathways as equipment and methodologies do not exist that would make these types of monitoring options technologically or economically practical. Post-closure monitoring procedures will be described with sufficient detail to show complete compliance with the 40 CFR 191 Assurance Requirements.

Appropriate monitoring information can be referenced in Chapter 2 of the NMVP, NMVP Appendices H, I, J, and K, and NMVP Addendum 6.0. Chapter D of the WIPP RCRA Permit Application also contains some discussion of monitoring programs that will require some modification to address disposal operations. 


\subsection{TEST PROGRAMS}

6.1 Status of Experimental Program Relevant to a Compliance Demonstration

\section{DISCUSSION:}

Discussions in this section will include a history of the WIPP experimental programs relevant to a compliance demonstration. This will include a listing of the experimental programs to date that have generated data/information that are used in the compliance evaluation(s). This discussion will include a list of experiments done, date completed, parameters measured or derived from experiments done, range values derived, and a statement of the true confidence in these values. 


\subsection{QUALITY ASSURANCE/QUALITY CONTROL PROGRAM}

7.1 Waste Characterization Program

7.2 Models and Codes

7.3 Experimental Programs

7.4 Facility Data Collection Programs

\subsubsection{Monitoring}

7.4.2 Site Characterization

\subsection{Facility Operations}

\section{DISCUSSION:}

A QA/QC plan that addresses all aspects of the compliance evaluation shall be prepared and included in the compliance documentation and must be approved by the EPA. Quality goals and the approaches used to meet the goals will be included for the following aspects of the compliance demonstration:

- Waste sampling and analysis activities

- Environmental monitoring activities

- $\quad$ Field measurements of the facility setting

- Validation of computations, codes, models, and methods used in calculating critical facility parameters, and assessing compliance with the standards

- Control of construction activities and evaluation of construction materials.

QA/QC goals are to be set for each of the following:

Data Representativeness: The degree to which data accurately and precisely represent characteristic populations.

Data Accuracy: The degree to which data agree with accepted reference or true values.

Data Precision: A measure of mutual agreement between comparable data.

Data Completeness: A measure of the amount of data collected versus the amount that was expected to be collected.

The EPA has stated that it will give greatest credence to data collected under approved QA/QC programs. Relevant QA/QC program discussions can be referenced in the NMVP in Chapters 2 and 3 . 


\subsection{COMPLIANCE ANALYSIS}

8.1 Methodology Used for Assessing Disposal System Performance

8.1.1 Conceptual Models

8.1.2 Numerical Models and Codes

\subsubsection{Validation \\ 8.1.2.2 Verification}

\subsubsection{Statistical Techniques}

8.1.4 Scenario Selection

8.1.5 Calculation of Regulatory Performance Measures

8.1.6 Uncertainty and Sensitivity Analyses

8.2 Reasonable Expectation/Reasonable Degree of Certainty

8.2.1 The Role and Use of Expert Judgement

8.2.2 Alternative Scenarios/Conceptual Models

8.2.3 Documentation of Assumptions

\subsection{Summary of Compliance Determination Data}

\section{DISCUSSION:}

\section{Title 40 CFR 268.6 Requirements}

The EPA does not provide any specific technical standards for the methodologies to be used in performing waste mobility modeling for demonstrations of no migration. It is, however, specified that the Disposal Phase NMVP must demonstrate, to a reasonable degree of certainty, that there will be no migration of hazardous constituents from the disposal unit for as long as the wastes remain hazardous. The DOE will describe waste mobility modeling techniques employed to complete and support the demonstration of no migration. The EPA provides general guidance regarding the use of waste mobility modeling techniques, and lists the minimum requirements for completeness of a demonstration of no migration. These completeness requirements are addressed in other sections of this table of contents.

It will be demonstrated that the chosen models are accurate and representative of the relevant waste constituents, and that all reasonable pathways to the unit boundary have been examined. Models, input data, and relevant documentation shall be discussed, substantiated, and made available to the EPA upon request and without restriction. The EPA will require that the 
following QA/QC information be used for each model employed in the assessment:

Model Confirmation and Calibration: A comparison of the results of analytical and numerical models with measured field results. Calibration in this context refers to adapting the model to the specific conditions of a facility relative to its location.

Justification of Assumptions: All assumptions will be properly justified. Reasonable conservatism will be used and must be demonstrated.

Sensitivity Tests: Models will be chosen that are influenced the most by the most important parameters.

Model Accuracy Assessment: The DOE will demonstrate that the model reasonably represents the actual physical system; there are no computational errors in the numerical codes employed; and that there is a high degree of correlation between the calculations and the measured data.

The EPA discourages the use of proprietary models, since the models selected will necessarily be closely scrutinized to determine their reasonableness and accuracy. In addition, the models will be submitted for public comment. The selected models shall be designed to accommodate two phase movement (that is, liquid and gas), and will be relatively simple models that can be used easily by the regulator to check the DOE's calculations. The key input parameters that the models use will be listed and discussed.

Relevant discussions of Waste mobility modeling are included in Chapters 4 and 5 of the NMVP.

Operational assessments were performed for use in the NMVP using models. Both the long-term and the short term versions of the model were used to calculate exposures due to routine operations and during short term events such as accidents. The model used must be re-evaluated to determine its appropriateness for the disposal phase operations.

An assessment of environmental impacts, simply stated, is a comparison of the modeling results to the appropriate health based standards for exposures to humans. This environmental assessment of potential impacts in essence constitutes the evaluations required for demonstrations of no migration. The EPA provided the appropriate health-based standards for the Test-Phase 
NMD since there were no published standards. The EPA has since proposed a set of health based standards as part of the RCRA Subpart S rulemaking (40 CFR 264, Subpart S). The appropriateness of using the proposed Subpart $S$ health based levels in WIPP assessments for disposal operations will be discussed with the EPA. Descriptive information relevant to the evaluation of environmental impacts can be referenced in Chapters 4 and 5 and Appendices $J$ and $M$ of the NMVP.

The EPA has specified that the potential for infrequent events during the period of time that the wastes will remain hazardous must be examined and the impacts assessed. Reasonably expected man-induced events will also be considered. In applying the "reasonably expected" criterion, the DOE has ruled out direct human intrusion into the repository as long as certain active and passive controls are exerted at the site of the facility. The EPA has accepted this for the purposes of nomigration modeling. The prediction of infrequent events and associated uncertainty analyses will be included and can be referenced in Chapter 6 of the NMVP.

\section{Title 40 CFR 191 Requirements}

The DOE will determine compliance with parts 191.13, 191.15, for Subpart B and Subpart C by evaluating long-term predictions of disposal system performance. The evaluation of compliance will be made through the use of performance assessments. The EPA defines a performance assessment as an analysis that identifies processes and events that could impact the performance of the disposal system, examines the potential impacts of any such events on performance, and estimates the cumulative releases of radionuclides while considering the associated uncertainties caused by significant processes and events. The estimates will be incorporated into an overall probability distribution of cumulative release to the extent practicable.

The EPA acknowledges that it is appropriate to use rather complex computational models, analytical theories, and expert judgement, as available. The EPA recognizes that sole reliance on the numerical predictions of the models may not be appropriate and that qualitative judgements may be used to supplement such predictions for compliance determinations. The EPA also acknowledges that no procedures for demonstrating compliance have been provided or tested.

The EPA assumes that when predicting disposal system performance, reasonable projections of the expected level of protection from engineered and natural barrier systems will be considered. The only portions of the disposal system that the implementing agency may disregard are portions 
of the system that make negligible contributions to the capability of the system to isolate the wastes. This will likely be difficult to defend without actually performing the calculation(s) to demonstrate negligibility.

The performance assessment will consider only those events that have a probability greater than one in 10,000 of occurring over a 10,000 year time period. Some release events may be omitted from the performance assessment if there is a reasonable expectation that the remaining probability distribution of cumulative releases will not be changed significantly by the omission. Omissions will be clearly explained and justified.

In the Title 40 CFR 191 Appendix B guidance, the EPA assumes that when practical the performance assessment results will be assembled into a Complementary Cumulative Distribution Function (CCDF) that indicates the probability of exceeding various levels of cumulative release. When the parametric uncertainties are considered, their effects can be incorporated into a single CCDF. If this single CCDF meets the 191.13(a) containment requirements, the disposal system will be considered in compliance.

In assessing compliance with the requirements of 191.15 and 191.16, "best estimates" (e.g., the mean or the median of the appropriate distribution, whichever is higher) for radiation exposures or radionuclide concentrations may be used.

The EPA clearly states that credit for active institutional controls in performance assessments cannot be taken after the first 100 year period. The EPA allows for the use of passive controls, but stipulates that they can never be assumed to eliminate the chance of inadvertent and intermittent human intrusion into disposal sites.

The EPA acknowledges that the most speculative potential disruptions are inadvertent human intrusions scenarios. The EPA also states that they believe that the most productive consideration of inadvertent intrusion concerns those realistic possibilities that may be usefully mitigated by repository design, site selection, or the use of passive controls.

The EPA specifies that the likelihood for inadvertent and intermittent drilling should be determined on a site-specific basis and should not be greater than 30 boreholes per square kilometer of repository area per 10,000 years for repositories that are situated close to sedimentary rock formations. The EPA also specifies that the consequences of such inadvertent 
drilling need not be assumed to be more severe than a direct release of all the available groundwater in the repository horizon that would promptly flow through the borehole to the surface driven by natural lithostatic pressure (or 200 cubic meters of groundwater if pumping is required), and creation of a pathway for groundwater flow typical of a borehole filled by indigenous gravel/soils that might be expected to settle into such a borehole over time had it been left open. These requirements may change with the promulgation of the Compliance Criteria for WIPP (40 CFR 194).

As required in the 40 CFR 268.6 standard, the EPA in general will require a demonstration that the implementing agency can reasonably expect that the repository will perform adequately to meet the 191 environmental protection standards for radionuclide contaminants. The methodologies used in assessing repository performance are not required to provide complete assurance. The models for 40 CFR 191 assessments, like those for 40 CFR 268.6 assessments, will be made available to the EPA without restriction. The required QA/QC information will likely be the same level required for 40 CFR 268.6 assessments as well. The conceptual models for 40 CFR 191 and 268.6 assessments will be identical. The conceptual $r$ dels will be closely scrutinized by the EPA and the public.

The DOE will describe an integrated approach to compliance document preparation. A flexible performance assessment process will be used to evaluate long term compliance with the standards. The compliance database and technical baseline will be used as the bases for conceptual model and model system development. The process will assess repository performance and identify and estimate parametric uncertainties.

Results from performance assessment modeling will be used in compliance analyses for prioritization and focusing of the experimental programs. The performance assessment results may also be used to modify existing experimental programs and/or to provide guidance to the generator facilities relative to repository waste envelope fluctuations that may allow for the use of innovative technologies in waste generation process modifications to ensure that future generated wastes will meet the WIPP Performance Based Waste Acceptance Criteria.

Performance assessment modeling will supplement the projections of repository performance. These program elements will feed the compliance database and the compliance technical baseline for the facility which will be used in supporting demonstrations of compliance. The compliance 
database will be revised until it is sufficiently mature to satisfy the regulatory requirements, demonstrate a thorough understanding of the natural processes and their interrelationships, define and defend the conceptual models of the naturally occurring processes, provide ranges and distributions of parameters for use in the calculations, and assess interactive processes between the repository contents and the renository geology.

The results of the performance assessment will be compared to the 40 CFR 191 release limits. If the 40 CFR 191 guidance for assessments of repository performance is adhered to and the DOE is reasonably certain that the facility will perform as expected, the compliance demonstration wil! be at hand. 


\subsection{REGULATORY COMPLIANCE ASSESSMENT}

9.1 Containment of Releases

9.1.1 40 CFR 191

9.1.2 40 CFR 268.6

9.2 Human Intrusion

9.2.1 40 CFR 191

9.2.2 40 CFR 268.6

9.3 Groundwater Protection

9.3.1 40 CFR 191

9.4 Individual Protection

9.4.1 40 CFR 191

9.5 Assurance Requirements

9.5.1 40 CFR 191

9.6 Monitoring Requirements

9.6.1 40 CFR 268.6

9.7 Infrequent Events and Processes

9.7.1 40 CFR 191

9.7.2 40 CFR 268.6

9.8 Program/Facility Modifications Designed to Increase Compliance Margin

9.9 Waste Acceptance/Waste Compliance

\section{DISCUSSION:}

The assessment of compliance will entail comparing available relevant information to the 1) appropriate health-based standards for the purposes of 40 CFR 268.6, and 2) appropriate radiation protection standards for the purposes of 40 CFR 191.

The results of the comparison of projected repository performance values to the regulatory requirements, while employing tools such as "reasonableness," will identify areas where 
compliance can be demonstrated and substantiated with information already available. It will also identify some areas where remaining uncertainties relative to repository performance are "unacceptable" and/or "unreasonable." The DOE will provide a logical, defensible, and substantiated argument for those areas where compliance is to be demonstrated. For those areas when the compliance assessment indicates unacceptable levels of uncertainty and/or unacceptable substantiating evidence for a "reasonable" argument that compliance can be achieved, addiiional data/information will be pursued. A potential alternative to additional data/information gathering activities is modification(s) to the program or facility that may increase compliance margin to an acceptable level. Risk screening techniques will be employed by the implementing agency in choosing the most feasible approaches. Waste related modifications may also be considered, as appropriate. 


\subsection{FUTURE TEST PROGRAMS}

10.1 Summary of Future Experimental Activities Necessary to Support a Compliance Demonstration

\section{DISCUSSION:}

This section will include a listing and description of the current experimental programs that are expected to provide data/information relevant to a current need identified in the compliance evaluation. The discussion will also include a listing of data/information needs driven by unacceptable levels of uncertainty and/or inadequate compliance margin that were identified in the compliance evaluation. Other potential drivers for additional information may be the need to reduce uncertainty relative to model assumptions, the identification of important model parameters not previously considered, results of sensitivity analyses indicating that parameters previously believed to be insignificant are potentially more significant than originally believed, or the emergence of new data not previously used in modeling activities. Any relevant schedule information shall be included as appropriate. 


\subsection{OTHER FEDERAL LAWS}

\section{DISCUSSION:}

This section will include information relative to the facility's overall environmental protection program to ensure that the applicable regulations can be effectively and efficiently implemented and enforced at a single facility. For example, rules enforced by the Occupational Safety and Health Administration (OSHA) are complementary to the protective measures that the DOE and the EPA might impose on operations of a regulated facility. The discussion here will be similar to that in Chapter $\mathrm{K}$ of the WIPP RCRA Permit Application (DOE/WIPP 91-005) and Chapter 2 of the WIPP No-Migration Variance Petition (DOE/WIPP 89-003).

\section{APPENDICES}

1. Relevant Plans and Procedures

2. Code and Model Details

3. Experimental Program Data, Manipulations, Calculations

4. Waste Characterization Data 

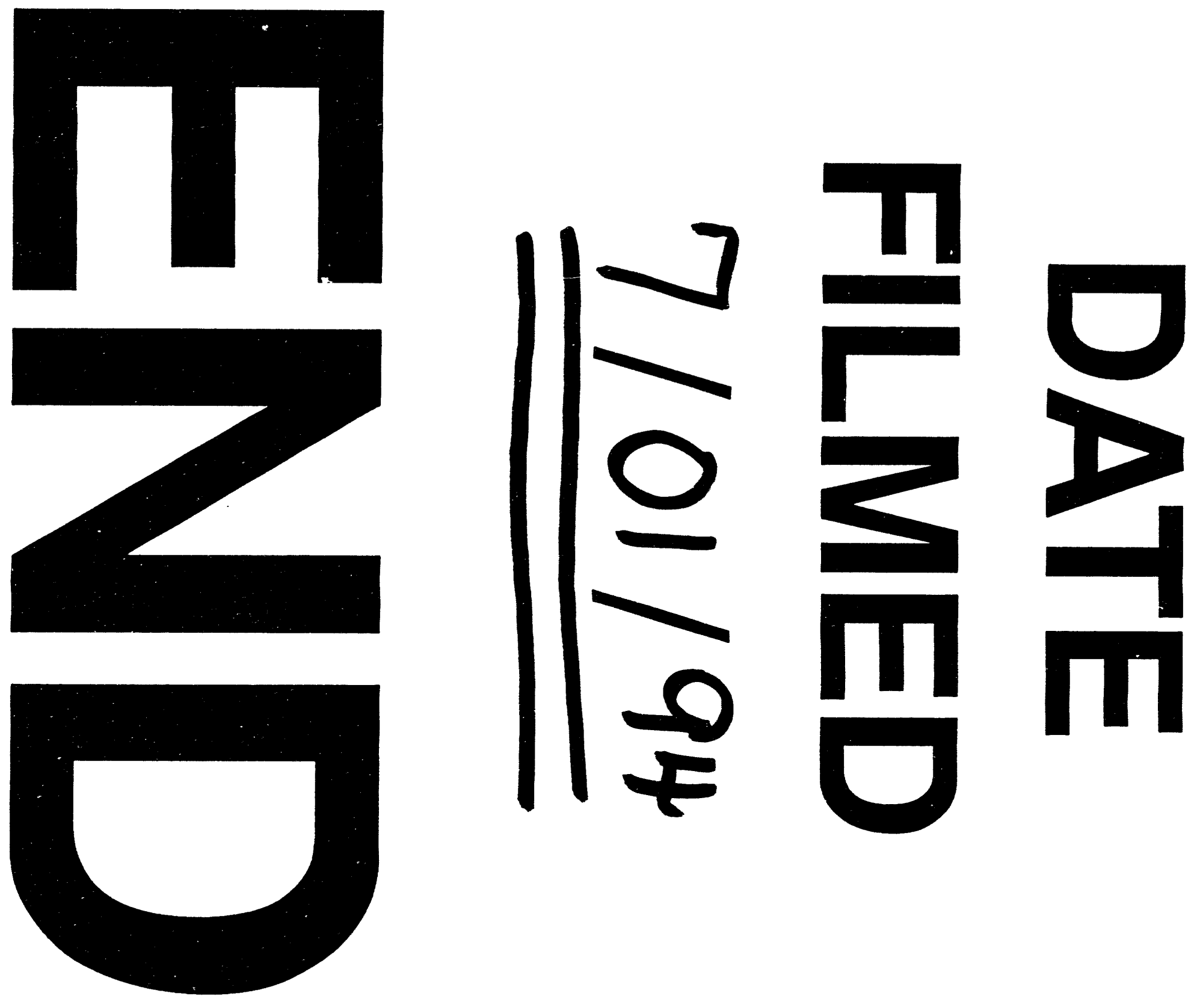
